\title{
DETEKSI DINI GANGGUAN PEMBATAS ARUS LISTRIK PADA PHB-TR BERTEGANGAN TINGGI BROADCAST SMS GATEWAY
}

\author{
${ }^{1}$ Mochammad Yusa, ${ }^{2}$ Joko Dwi Santoso \\ ${ }^{1}$ Informatika/Fakultas Teknik, Universitas Bengkulu, Jl. WR Supratman Kandang Limun Sungat Serut Bengkulu \\ ${ }^{2}$ Teknik Komputer / Ilmu Komputer, Universitas AMIKOM Yogyakarta, Jl. Ring Road Utara, Condong Catur, \\ Sleman, Yogyakarta, 55283 \\ $(0274-884201-207 ; 0274-884208)$

Abstrak - Gangguan pecahnya NH FUSE atau pembatas arus listrik di PHB-TR jika tidak cepat ditangani tentu menimbulkan kerugian, tegangan di bawah standar yang menyebabkan eletronic eqiupment mudah rusak, dan peralatan distribusi aset PLN yang juga akan rusak trafo. Salah satu faktor penting yang bisa terjadi adalah keterlambatan informasi yang diterima oleh petugas PLN dan pelanggan tidak segera repot ke kantor PLN. Gangguan pecahnya sistem peringatan dini NH FUSE menggunakan SMS gateway berbasis sensor tegangan, yang dirancang untuk memberikan informasi sedini mungkin gangguan, bertujuan agar dapat ditangani dengan cepat sehingga kerusakan pelanggan peralatan elektronik dan transformator aset PLN dapat diminimalisir.

Kata Kunci: Disruption of NH FUSE, Microcontroller, SMS Gateway.

Abstract - Disruption rupture of NH FUSE or delimiter the electrical current in the PHB-TR if not quickly dealt necessarily lead to losses, voltage below the standards that cause electronic equipment be easily damaged, and distribution equipment PLN asset that will also be damaged transformer. One of the important factors it can happen is delay the received information by PLN officer and customers do not immediately repot to the office of PLN. Early warning system disruption rupture of NH FUSE using a voltage sensor-based SMS gateway, designed to provide information as early as possible disturbance, aims to can be handled quickly so that damage to electronic equipment customers and transformer PLN asset can be minimized.
Keywords - Disruption of NH FUSE, Microcontroller, SMS Gateway.

\section{PENDAHULUAN}

1.1 Latar Belakang

Peralatan Hubung Bagi-Tegangan Rendah atau PHB-TR berfungsi untuk membagi tenaga listrik tegangan redah menjadi beberapa jurusan yang selanjutnya didistribusikan ke Jaringan Tegangan Rendah. Peralatan penting dalam PHBTR memiliki peranan yang berbeda-beda. Saklar utama memiliki fungsi sebagai pemutus arus listrik yang masuk dari trafo, Busbar sebagai penyalur dari saklar utama menuju NH FUSE, dan NH FUSE sebagai pembatas arus listrik sekaligus pelindung trafo jika ada arus lebih. 
Jurnal Pseudocode, Volume VII Nomor 2, September 2020, ISSN 2355-5920, e-ISSN 2655-1845 www.ejournal.unib.ac.id/index.php/pseudocode

Gangguan didalam PHB-TR lebih banyak disebabkan oleh NH FUSE yang putus.Salah satu faktor penyebab putusnya NH FUSE adalah gangguan pada Jaringan Tegangan Rendah (JTR), sebagai contoh pohon yang menimpa jaringan, layang-layang dan los kontak pada JTR sehingga menyebabkan beban lebih.

Gangguan putusnya NH FUSE bila tidak cepat ditangani tentunya menyebabkan banyak kerugian baik dari pihak pelanggan maupun pihak PLN, antara lain peralatan elektronik milik pelanggan mudah rusak akibat tegangan dibawah standart, sedangkan dari pihak PLN dapat merusak peralatan distribusi yaitu trafo atau transformator. Hal ini terjadi karena beberapa faktor yaitu keterlambatan informasi yang diterima petugas PLN maupun pelanggan bula terjadi gangguan.

Melihat kondisi ini, maka diperlukan adanya rancangan sebuah alat yang efisien dalam memberikan informasi untuk mendeteksi terjadinya gangguan pada NH FUSE guna mencegah semua kerugian yang diakibatkan oleh gangguan putusnya NH FUSE.

Dalam hal ini sistem yang akan dirancang adalah sistem yang dapat mendeteksi terjadinya gangguan putusnya NH FUSE dan mengindikasi gangguan dengan peringatan dini menggunakan sensor pendeteksi tegangan yang kemudian memberikan informasi kepada pihak terkait, melalui pesan singkat (SMS) ke telpon selular petugas PLN (Supervisor Teknik) atau pelanggan terdekat jika terdeteksi bahwa salah satu tegangan dari NH FUSE tersebut hilang.

Berdasarkan latar belakang yang telah disampaikan, maka perlu dirumuskan suatu masalah yang akan diselesaikan pada penelitian ini yaitu:
1. Bagaimana merancang sistem yang dapat mendeteksi dan memberikan informasi terjadinya gangguan putusnya NH FUSE sejak dini berupa sms gateway menggunakan mikrokontroller ?

2. Bagaimana merancang proses eksekusi data pada mikrokontroler pendeteksi tegangan agar dapat memberikan perintah kepada modem sehingga dapat mengirimkan informasi berupa sms gateway?

3. Bagaimana mengukur tingkat keberhasilan sistem pendeteksi tegangan dalam mengirim informasi berupa sms gateway?

\section{LANDASAN TEORI}

2.1. Hardware

\subsubsection{PHB-TR}

PHB-TR adalah suatu kombinasi dari satu atau lebih Perlengkapan Hubung Bagi Tegangan Rendah dengan peralatan kontrol, peralatan ukur, pengaman dan kendali yang saling berhubungan. Keseluruhannya dirakit lengkap dengan sistem pengawatan dan mekanis pada bagian-bagian penyangganya. Secara umum PHB TR sesuai SPLN 118-3-11996, untuk pasangan dalam adalah jenis terbuka. Rak TR pasangan dalam untuk gardu distribusi beton. PHB jenis terbuka adalah suatu rakitan PHB yang terdiri dari susunan penyangga peralatan proteksi dan peralatan Hubung Bagi dengan seluruh bagian-bagian yang bertegangan, terpasang tanpa isolasi. Jumlah jurusan per transformator atau gardu distribusi sebanyak-banyaknya 8 jurusan, disesuaikan dengan besar daya transformator dan Kemampuan Hantar Arus (KHA) 
Jurnal Pseudocode, Volume VII Nomor 2, September 2020, ISSN 2355-5920, e-ISSN 2655-1845 www.ejournal.unib.ac.id/index.php/pseudocode

Penghantar JTR yang digunakan. Pada PHB-

TR harus dicantumkan diagram satu garis, arus pengenal gawai proteksi dan kendali serta nama jurusan JTR.[ 4 ]

\subsubsection{SMS (Short Message Service)}

Menurut Cahyo (2006) Short Message Service (SMS) adalah bagian atau fitur dari GSM, dan merupakan teknologi yang memungkinkan pengiriman dan penerimaan pesan (message) dalam bentuk teks antar mobile phone [7].

\section{A. SMS Gateway}

SMS Gateway merupakan pintu gerbang bagi penyebaran informasi dengan menggunakan SMS. Dengan SMS gateway dapat menyebarkan pesan ke banyak nomor secara otomatis dan cepat yang langsung terhubung dengan database nomor-nomor ponsel saja, tanpa harus mengetik ratusan nomor dan pesan di ponsel, karena semua nomor akan diambil secara otomatis dari database tersebut. Selain itu dengan adanya SMS Gateway, dapat mengelola pesan-pesan yang akan dikirim. Dengan menggunakan program tambahan yang dapat dibuat sendiri, pengirim pesan dapat lebih fleksibel dalam mengirim berita, karena pesan yang akan dikirim berbeda-beda untuk masing-masing penerimanya (Tarigan, 2012).[ 8 ]

\subsubsection{Mikrokontroller ATMega 8535}

Mikrokontroller ATMega 8535 adalah mikrokontroller CMOS 8 bit daya rendah berbasis arsitektur RISC. Intruksi dikerjakan pada satu siklus clock, ATMega 8535 mempunyai throughput mendekati 1 MIPS per $\mathrm{MHz}$, hal ini membuat ATMega 8535 dapat bekerja dengan kecepatan tinggi walaupun dengan penggunaan daya rendah.

\subsubsection{Sensor Optik/ Sensor Optocoupler}

Optocoupler merupakan salah satu jenis komponen yang memanfaatkan sinar sebagai pemicu on/off-nya.Opto berarti optic dan coupler berarti pemicu. Sehingga bisa diartikan bahwa optocoupler merupakan suatu komponen yang bekerja berdasarkan picu cahaya optic opto-coupler termasuk dalam sensor. Pada dasarnya Optocoupler terdiri dari 2 bagian utama yaitu Transmitter yang berfungsi sebagai pengirim cahaya optik dan receiver yang berfungsi sebagai pendeteksi sumber cahaya [12].

\subsubsection{Modem SIM 900A}

Modem yang digunakan sistem berfungsi mengirimkan SMS yang berisikan peringatan jika terjadi deteksi gangguan $\mathrm{NH}$ FUSE pada mikrokontroler ke User. Modem digunakan untuk pengiriman data yang menggunakan sistem GPRS. Modem dikontrol dengan menggunakan AT-Commands. SIM900 GSM/GPRS dikontrol melalui perintah AT (GSM 07.07, 07.05, dan SIMCOM).[13]

\subsection{Software}

\subsubsection{Command}

AT Command berperan di balik tampilan menu messages sebuah ponsel yang bertugas mengirim/menerima data ke/dari SMS-Center. Salah satu software yang dapat digunakan untuk menguji AT Command ini adalah Windows HyperTerminal. Salah satu hal yang perlu diperhatikan dalam pengujian 
Jurnal Pseudocode, Volume VII Nomor 2, September 2020, ISSN 2355-5920, e-ISSN 2655-1845 www.ejournal.unib.ac.id/index.php/pseudocode

ini adalah nilai properties yang harus diisi yang bergantung pada jenis alat komunikasi yang digunakan, misalnya ukuran bit per second rate dari sms device yang dipergunakan. AT Command untuk sms biasanya diikuti oleh data I/O yang diwakili oleh unit-unit PDU.

\subsubsection{Code Vision AVR}

CodeVisionAVR adalah sebuah compiler $\mathrm{C}$ yang telah dilengkapi dengan fasilitas Integrated Development Environment (IDE) dan didesain agar dapat menghasilkan kode program secara otomatis untuk mikrokontroler Atmel AVR. Program ini dapat berjalan dengan menggunakan sistem operasi Windows ${ }^{\circledR}$ XP, Vista, Windows 7, dan Windows 8, 32-bit dan 64-bit

\section{ANALISA DAN PERANCANGAN}

\subsection{Analisis Masalah}

Gangguan didalam PHB-TR lebih banyak disebabkan karena pembatas arus listrik (NH FUSE) yang putus. Salah satu faktor penyebab putusnya adalah gangguan pada Jaringan Tegangan Rendah (JTR), antara lain pohon yang menimpa jaringan, layang-layang, JTR putus, dan los kontak pada JTR yang menyebabkan beban lebih.

Gangguan putusnya pembatas arus listrik (NH FUSE) bila tidak cepat ditangani tentunya menyebabkan banyak kerugian baik dari pihak pelanggan maupun PLN, antara lain peralatan elektronik milik pelanggan mudah rusak karena tegangan yang dihasilkan dibawah standart, sedangkan dari pihak PLN dapat merusak peralatan distribusi yaitu trafo.

\subsubsection{Solusi Penyelesaian Masalah}

Melihat maslah diatas, maka diperlukan adanya penyelesaian masalah atau solusi dari masalah tersebut. Dalam hal ini penulis memberikan solusi untuk masalah tersebut berupa rancangan sebuah alat yang efisien dalam memberikan informasi untuk mendeteksi terjadinya gangguan pembatas arus listrik (NH FUSE) guna mencegah semua kerugian yang diakibatkan. Dengan sistem yang dapat mengindikasi dan mendeteksi gangguan sistem peringatan dini ini menggunakan sensor pendeteksi yang kemudian menginformasikan kepada pelanggan dan pihak PLN (Supervisor Teknik), melalui pesan pendek (SMS) ke telpon seluler. Dalam solusi ini diharapkan gangguan dapat ditangani dengan cepat dan sedini mungkin.

3.2 Requirement

Sesuai dengan metode penelitian yang penulis gunakan dalam perancangan sistem peringatan dini gangguan pembatas arus listrik (NH FUSE) pada PHB-TR, maka pada tahap yang pertama yaitu tahap Requirement (Kebutuhan). Dalam tahap ini setelah analisis masalah (kendala) dan analisis solusi.

\subsection{Analisis Kebutuhan}

\subsubsection{Analisis Fungsional}

Kebutuhan Fungsional sistem adalah aktifitas dan pelayanan yang harus dimiliki oleh sebuah sistem berupa input, proses, output, maupun penyimpanan data. Berdasarkan kebutuhan sistem secara fungsional, rancangan prototype peringatan dini gangguan pada NH FUSE harus mampu 
Jurnal Pseudocode, Volume VII Nomor 2, September 2020, ISSN 2355-5920, e-ISSN 2655-1845 www.ejournal.unib.ac.id/index.php/pseudocode

memenuhi kebutuhan fungsional sebagai berikut:

1. Alat mempu mendeteksi nyala dan mati LED (indikator tegangan) menggunakan sensor optocoupler.

2. Sensor mampu mengirimkan data deteksinya ke ATMega 8535.

\subsubsection{Analisis Non Fungsional}

Kebutuhan non fungsional sistem adalah karakteristik atau batasan yang menentukan kepuasan sebuah sistem seperti kinerja, kemudahan penggunaan, biaya, dokumentasi, kontrol, dan kemampuan sistem bekerja tanpa mengganggu fungsionalitas sistem lainnya.

Berikut analisis non fungsional:

1. Desain fisik perangkat simple, tidak memerlukan tempat yang besar.

2. Memerlukan tegangan listrik sesuai standart dari PLN, yaitu 220 volt.

\subsection{Analisis Kelayakan}

Tidak semua kebutuhan yang didefinisikan pada tahapan analisis kebutuhan layak untuk dikembangkan pada perangkat ini. Harus ada mekanisme untuk menjastifikasi apakah kebutuhan yang dibuat layak untuk dilanjutkan atau tidak. Ada beberapa kriteria kelayakan yang bisa ditinjau, misalnya kelayakan teknologi dan kelayakan operasional

\subsection{Blok Diagram Rangkaian}

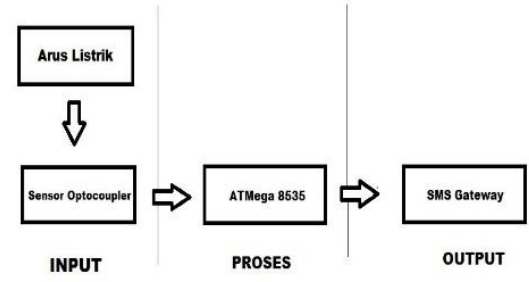

Gambar 1. Prinsip Kerja dari Rangkaian

\subsection{Flowchart Sistem}

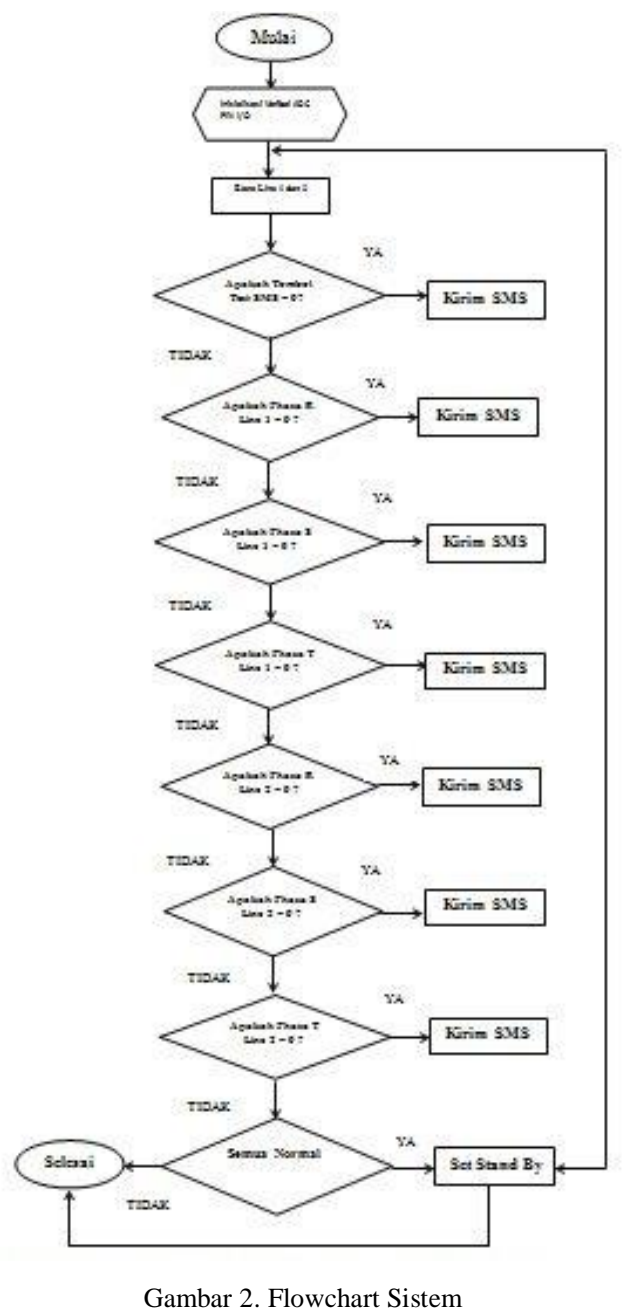

IV. IMPLEMENTASI DAN PEMBAHASAN

\subsection{Blok Masukan (Input)}

Blok masukan (input) terdiri dari arus listrik yang berfungsi untuk menghidupkan seluruh rangkaian sedangkan sensor optik atau optocoupler berfungsi untuk mendeteksi adanya indikasi gangguan arus listrik yang padam dengan indikator LED akibat putusnya pembatas arus listrik. Blok masukan dialiri arus listrik ditandai dengan nyalanya saklar power dan saklar line 1 dan line 2 pada rangkaian yang ada pada alat tersebut. 
Jurnal Pseudocode, Volume VII Nomor 2, September 2020, ISSN 2355-5920, e-ISSN 2655-1845 www.ejournal.unib.ac.id/index.php/pseudocode

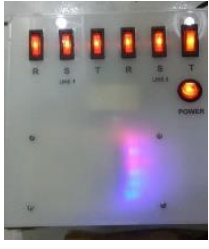

Gambar 3. Blok Masukan (Input)

\subsection{Blok Proses}

Blok proses terdapat pada mikrokontroller ATMega 8535. Didalam mikrokontroller ATMega 8535 terdapat PIN yang masing-masing mempunyai fungsi sebagai masukan informasi dari sensor optik atau optocoupler. PIN input yaitu berfungsi sebagai masukan informasi dari sensor optik atau optocoupler yang kemudian diproses dan menghasilkan output.

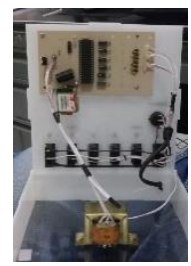

Gambar 4. Blok Proses

\subsection{Blok Keluaran (Output)}

Blok keluaran terdiri dari pesan singkat SMS Gateway menggunakan Modem SIM 900A sebagai informasi adanya deteksi gangguan pada $\mathrm{NH}$ FUSE (hilangnya arus listrik) yang diterima oleh sensor yang kemudian telah diproses oleh ATMega 8535.

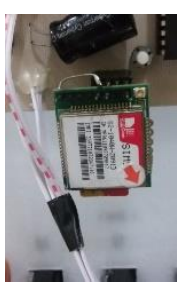

Gambar 5. Blok Keluaran (Output)
4.4 Pengujian

4.4.1 Pengujian Provider

Tabel 1. Pengujian Provider

\begin{tabular}{|c|c|c|c|}
\hline Pengujian & Jenis Provider & $\begin{array}{c}\text { Lama waktu } \\
\text { yang Di } \\
\text { Butuhkan }\end{array}$ & Hasil Pengujian \\
\hline 1 & Telkomsel & 5 Detik & SMS Berhasil Terkirim \\
\hline 2 & Telkomsel & 7 Detik & SMS Berhasil Terkirim \\
\hline 3 & Indosat & 13 Detik & SMS Berhasil Terkirim \\
\hline 4 & Indosat & 11 Detik & SMS Berhasil Terkirim \\
\hline 5 & $\mathrm{XL}$ & 14 Detik & SMS Berhasil Terkirim \\
\hline 6 & $\mathrm{XL}$ & 20 Detik & SMS Berhasil Terkirim \\
\hline
\end{tabular}

Tujuan dilakukannya pengujian dan analisa pengiriman sms ini adalah untuk mendapatkan parameter lamanya waktu yang dibutuhkan modem untuk mengirim sms sampai ke user berdasarkan provider kartu perdana yang berbeda-beda. Dengan dilakukannya pengujian ini diharapkan modem dapat mengirim sms secepat mungkin menggunakan provider kartu perdana yang memiliki performa setabil.

\subsubsection{Pengujian LED Indikator}

Tabel 2. Pengujian LED Indikator

\begin{tabular}{|c|l|}
\hline Pengujian & Hasil Pengujian LED \\
\hline Tombol Test SMS $\rightarrow$ Tekan & Nyala \\
\hline Line 1 $\quad($ R $\rightarrow$ Mati & Nyala \\
\hline$($ S $\rightarrow$ Mati & Nyala \\
\hline (T) $\rightarrow$ Hidup & Mati \\
\hline Line $2 \quad($ R $) \rightarrow$ Mati & Nyala \\
\hline$($ S $) \rightarrow$ Hidup & Mati \\
\hline$(T) \rightarrow$ Mati & Nyala \\
\hline
\end{tabular}

Tujuan diadakannya pengujian dan analisa kerja LED adalah untuk melihat sejauh mana kemampuan dan ketahanan dari LED tersebut, dimana LED tersebut memiliki peran sebagai lampu indikator bila hilangnya arus listrik. Dalam sistem ini, LED indikator berfungsi untuk memberikan pemberitahuan bila salah satu phasa atau lebih dari Line 1 (RST) dan Line 2 (RST) kehilangan tegangan. Jika salah satu phasa atau lebih kehilangan tegangan otomatis LED indikator 
Jurnal Pseudocode, Volume VII Nomor 2, September 2020, ISSN 2355-5920, e-ISSN 2655-1845 www.ejournal.unib.ac.id/index.php/pseudocode

ini akan menyala sebagai sinyal pemeritahuan bahwa terjadi gangguan, sekaligus awal proses pengiriman notifikasi SMS ke nomor ponsel yang telah ditentukan.

\subsubsection{Pengujian Sensor Optik/Optocoupler}

Tabel 3. Pengujian Sensor Optik/Optocoupler

\begin{tabular}{|c|l|l|}
\hline Percobaan & Kondisi LED & Kondisi Sensor \\
\hline Line 1 (R) & Mati & Nyala \\
\hline$($ S) & Nyala & Mati \\
\hline$(\mathrm{T})$ & Mati & Nyala \\
\hline Line 2 (R) & Nyala & Mati \\
\hline$(\mathrm{S})$ & Nyala & Mati \\
\hline$(\mathrm{T})$ & Mati & Nyala \\
\hline
\end{tabular}

Pengujian Sensor optik/optocoupler dilakukan pengambilan data percobaan untuk melihat sejauh mana sensor tersebut dapat bekerja dengan optimal. Prinsip dari sensor optik yaitu menerima sinar inframerah dari LED indikator dari masingmasing Line 1 dan 2, dan bila LED tersebut padam maka sensor optik akan bekerjadan ciri-ciri sensor tersebut masih baik yaitu lampu indikator sensor optik akan menyala.

\section{KESIMPULAN}

\subsection{Kesimpulan}

Setelah melakukan pengujian dan analisa terhadap perancangan ptototype sistem peringatan dini gangguan putusnya pembatas arus listrik pada PHB-TR menggunakan sensor optik/optocoupler, penulis mencoba untuk menarik kesimpulan sebagai berikut:

1. Perancangan prototype sistem peringatan dini gangguan putusnya pembatas arus listrik telah berhasil dibangun dengan menggunakan metode penelitian yang ditetapkan pada Bab 1.

2. Pengiriman SMS dari modem SIM 900A ke ponsel user berhasil dikirim dengan rata-rata lama waktu yang dibutuhkan adalah 6 detik menggunakan provider Telkomsel.
Pada sensor optik/optocoupler sangat sensitif dalam mendeteksi kondisi LED on/off, LED merupakan sebagai indikator arus listrik yang masuk ke dalam rangkaian. Ketika LED dalam kondisi padam atau off, dengan cepat sensor optik mendeteksi bahwa ada arus listrik yang putus, dengan begitu sensor optik akan mengirimkan data kepada ATmega 8535, dan diteruskan ke modem SIM 900A untuk memberikan informasi kepada pihak terkait.

\section{DAFTAR PUSTAKA}

[1] Rizal Mery Subito, "Alat Pengukuran Pemakaian Energi Listrik Menggunakan Sensor Optocoupler dan Mikrokontroller AT89S52," Jurnal Ilmiah Foristek, vol. 2, no. 2, pp. 184-189, September 2012.

[2] Balza Ahcmad, "Sistem Alarm Mobil Menggunakan Mikrokontroller AT89S52 Berbasis SMS," TELKOMUNIKA, vol. 6, no. 1, pp. 15-20, April 2008.

[3] Winayu Siswanto, Parluhutan Samosir Ratno Wibowo, Standar Kontruksi Gardu Distribusi Dan Gardu Hubung Tenaga Listrik, 4th ed. Jakarta, Indonesia: PT.PLN (PERSERO), 2010.

[4] Winayu Siswanto, Parluhutan Samosir Ratno Wibowo, Standart Kontruksi Gardu Distribusi Dan Gardu Hubung Tenaga Listrik, 4th ed. Jakarta, Indonesia: PT.PLN (PERSERO), 2010.

[5] Winayu Siswanto, Parluhutan Samosir Ratno Wibowo, Standar Kontruksi Gardu Distribusi Dan Gardu Hubung Tenaga Listrik, 4th ed. Jakarta, Indonesia: PT.PLN (PERSERO), 2010.

[6] Wiranto Herry Utomo, Theophilus Wellem Cahyo Rossy W, "Perancangan dan Implementasi Sistem Informasi Layanan Short Messaging Service (SMS)," Jurnal Informatika, vol. 2, no. 2, pp. 155-166, Desember 2006.

[7] D.E. Tarigan, Membangun SMS Gateway Berbasis Web dengan Codeigniter. Yogyakarta, Indonesia: Lokomedia, 2012.

[8] ATMEL, Feature ATMega 8535, ATMEL Corporation, Ed. Orchard Parkway San Jose, USA: ATMEL Corporation, 2006 
Jurnal Pseudocode, Volume VII Nomor 2, September 2020, ISSN 2355-5920, e-ISSN 2655-1845 www.ejournal.unib.ac.id/index.php/pseudocode

[9] ATMEL, Overview ATMega 8535, ATMEL Corporation, Ed. Orchard Parkway San Jose, USA: ATMEL Corporation, 2006.

[10] ATMEL, Pin Description ATMega 8535, ATMEL Corporation, Ed. Orchard Parkway San Jose, USA: ATMEL Corporation, 2006.

[11] Rizal Mery Subito, "Alat Pengukuran Pemakaian Energi Listrik Menggunakan Sensor Optocoupler dan Mikrokontroller AT89S52," Jurnal Ilmiah Foristek, vol. 2, no. 2, pp. 184-189, September 2012.

[12] Depema Ginting Hidayat, "Sistem Pemantauan Shelter BTS Berbasis Mikrokontroler dan Web," Jurusan Teknik Komputer Unikom, vol. 1, pp. 1-7, Oktober 2013.

[13] SIM900_GSM, "SIM900 GSM Location AT Command Manual," SIM900, vol. 1, pp. 1-8, Januari 2011.

[14] Salwin Anwar, "Variabel Tegangan Terhadap Hasil Electroplating," POLI REKAYASA, vol. 4, no. 1, pp. 1858-3709, Oktober 2008.
[15] Telit Wireless Solution. (2006, Agustus) AT Commands Refrences Guide. [Online]. https://www.sparkfun.com/datasheets/Cellular\%20Mod ules/AT_Commands_Reference_Guide_r0.pdf. [Accesed Maret 2016]

[16] HP Info Tech. (2007, Desember) Pengenalan CodeVision AVR. [Online]. https://www.unidue.de/ hl271st/Lehre/SMR/cvavr_manual.pdf. [Accesed Maret 2016]

[17] HP Info Tech. (2007) CodeVision AVR User Manual, Data type. [Online]. https://www.unidue.de/ hl271 st/Lehre/SMR/cvavr_manual.pdf. [Accesed Maret 2016]

[18] Sarah Cox, Larry O Richard

[19] Barnett and cull, Embeded C Programming and The Atmel AVR, 2e. United State: Delmar Cangage Learning, 2006. 